\title{
Formulation and Characterization of Fast Dissolving Tablet of Salbutamol Sulphate
}

\author{
Meenakshi Bharkatiya ${ }^{1,}$,, Santosh Kitawat ${ }^{2}$, Kalpesh Gaur ${ }^{2}$ \\ ${ }^{1}$ B. N. Institute of Pharmaceutical Sciences, Udaipur-313001, Rajasthan, India \\ ${ }^{2}$ Geetanjali Institute of Pharmacy, Geetanjali University, Udaipur-313002, Rajasthan, India \\ *Corresponding author: meenakshibharkatiya@ rediffmail.com
}

\begin{abstract}
There is an increasing demand for more patient compliant dosage form and a novel method is the development of orally disintegrating tablets which dissolve or disintegrates instantly on the patient tongue or buccal mucosa. It is suited for tablets undergoing high first pass metabolism and is used for improving bioavailability with reducing dosing frequency to minimize side effect and make it more cost effective. Oral route having the highest patient compliance is regarded as the most convenient, safest and also the most economical method of drug delivery. Fast dissolving tablets are one such most advantageous example of the oral drug delivery. These tablets readily dissolve or disintegrate in the saliva i.e. within less than $60 \mathrm{sec}$ without the need for water. In the present study fast dissolving tablet of Salbutamol Sulphate was formulated, prepared and evaluated. The objective was to fabricate the fast dissolving tablet for rapid release of drug, their characterization, and in-vitro drug release studies. Salbutamol Sulphate being a water soluble drug would be readily available in a dissolved form for rapid oral uptake. The rapid dissolving concept in case of Salbutamol Sulphate could be of a great importance in reliving acute asthmatic shocks. The drug was analyzed by UV, IR and DSC studies. The drug sample was found to comply with all the specifications. The tablets were formulated by using different super disintegrants, in different ratio by various techniques like direct compression, sublimation and solid dispersion. The blends were evaluated for mass volume relationship, flow properties and for compressibility properties. The tablets were evaluated for various physicochemical characteristics like color, odor, thickness, diameter, visual inspection for any defects, weight variation, hardness, friability, disintegration time and wetting time. The tablets were also evaluated for uniformity of drugs content and in-vitro drug release. In conclusion, the tablets prepared by solid dispersion method with crospovidone as a superdisintegrant shows better release profile as compared to other techniques.
\end{abstract}

Keywords: orally disintegrating tablets, Salbutamol, acute asthmatic shocks, superdisintegrant

Cite This Article: Meenakshi Bharkatiya, Santosh Kitawat, and Kalpesh Gaur, "Formulation and Characterization of Fast Dissolving Tablet of Salbutamol Sulphate." American Journal of Pharmacological Sciences, vol. 6, no. 1 (2018): 1-6. doi: 10.12691/ajps-6-1-1.

\section{Introduction}

Fast dissolving tablets (FDTs) are solid single-unit dosage forms that are placed in mouth, allowed to disperse/dissolve in the saliva without the need of water and provide a quick onset of action. Some drugs are absorbed from mouth, pharynx and oesophagus as the saliva passes down into the stomach. In such cases, bioavailability of drug is significantly greater than those observed from conventional tablet dosage form. FDTs are appreciated by a significant segment of population, particularly children and elderly, which have difficulty in swallowing conventional tablets or capsules $[1,2,3]$. FDTs are prepared by various techniques, mainly direct compression, lyophilization and moulding. The simplicity and cost effectiveness of the direct compression process have positioned this technique as an attractive alternate to traditional granulation technologies [4]. Usually superdisintegrants are added to a drug formulation to facilitate the break-up or disintegration of tablet into smaller particles that can dissolve more rapidly than in absence of disintegrants [5].

US Food and Drug Administration Center for Drug Evaluation and Research (CDER) defines, in the "Orange Book," an ODT as "a solid dosage form containing medicinal substances, which disintegrates rapidly, usually within a matter of seconds, when placed upon the tongue." European Pharmacopoeia described ODTs as "uncoated tablets intended to be placed in the mouth where they disperse rapidly before being swallowed" and as tablets which should disintegrate within 3 minutes [6]. Fast disintegrating tablets (FDTs) are also known as "fast dissolving," "mouth dissolving," "rapid dissolve," "quick disintegrating," "orally disintegrating," "rapimelt," "fast melts," "orodispersible," "melt in mouth," "quick dissolving," "porous tablets," "EFVDAS," or "effervescent drug absorption system" [7].

The bioavailability of drugs may be increased due to absorption of drug in oral cavity and also due to pregastric absorption of saliva containing dispersed drugs that pass down into the stomach. Moreover, the amount of drug that is subjected to first-pass metabolism is reduced as 
compared to standard tablet [8]. The target populations for these new fast-dissolving/disintegrating dosage forms have generally been pediatric, geriatric, and bedridden or mentally disabled patients. Patients with diarrhea, persistent nausea, or vomiting, who are traveling, or who have little or no access to water are also good candidates for FDTs [9].

The basic approach in development of FDT is the use of super disintegrates like cross linked carboxymethyl cellulose (croscarmellose), sodium starch glycolate (primogel, explotab), polyvinylpyrollidone (polyplasdone) etc, which provide instantaneous disintegration of tablet after putting on tongue, their by release the drug in saliva. The bioavailability of some drugs may be increased due to absorption of drug in oral cavity and also due to pregastric absorption of saliva containing dispersed drugs that pass down into the stomach. More ever, the amount of drug that is subjected to first pass metabolism is reduced as compared to standard tablet [10].

\section{Methods}

\subsection{Preparation of Fast Dissolving Tablets of Salbutamol Sulphate}

The critical parameters to formulate a fast dissolving tablet are choice of super disintegrants and optimization of concentration of superdisintegrants. The super disintegrant (Crospovidone, Sodium Starch Glycolate, Ac di sol) in varying concentration (4 and $6 \mathrm{mg}$ ) were used to develop the tablets. Fast dissolving tablets were prepared by direct compression, sublimation and solid dispersion methods. 4 mg Salbutamol sulphate was taken in all the formulations. The compositions of tablets were shown in Table 1, Table 2 and Table 3 respectively.

Table 1. Formulation of fast dissolving tablets of Salbutamol Sulphate by direct Compression Technology

\begin{tabular}{|l|c|c|c|c|c|c|}
\hline Ingredients (mg) & A1 & A2 & A3 & A4 & A5 & A6 \\
\hline Salbutamol sulphate & 4 & 4 & 4 & 4 & 4 & 4 \\
\hline Sodium Starch Glycolate & 4 & 6 & & & & \\
\hline Crosprovidone & & & 4 & 6 & & \\
\hline Ac di sol & & & & & 4 & 6 \\
\hline Avicel-PH 102 & 34 & 34 & 34 & 34 & 34 & 34 \\
\hline Mannitol & 52 & 50 & 52 & 50 & 52 & 50 \\
\hline Talc & 1 & 1 & 1 & 1 & 1 & 1 \\
\hline Magnesium Stereate & 0.2 & 0.2 & 0.2 & 0.2 & 0.2 & 0.2 \\
\hline
\end{tabular}

Table 2. Formulation of fast dissolving tablets of Salbutamol Sulphate by Sublimation Technology

\begin{tabular}{|l|c|c|c|c|c|c|}
\hline Ingredients (mg) & B1 & B2 & B3 & B4 & B5 & B6 \\
\hline Salbutamol sulphate & 4 & 4 & 4 & 4 & 4 & 4 \\
\hline Camphor & 4 & 4 & 4 & 4 & 4 & 4 \\
\hline Sodium Starch Glycolate & 4 & 6 & & & & \\
\hline Crosprovidone & & & 4 & 6 & & \\
\hline Ac di sol & & & & & 4 & 6 \\
\hline Avicel-PH 102 & 34 & 34 & 34 & 34 & 34 & 34 \\
\hline Mannitol & 52 & 50 & 52 & 50 & 52 & 50 \\
\hline Talc & 1 & 1 & 1 & 1 & 1 & 1 \\
\hline Magnesium Stereate & 0.2 & 0.2 & 0.2 & 0.2 & 0.2 & 0.2 \\
\hline Sodium Saccharine & 0.8 & 0.8 & 0.8 & 0.8 & 0.8 & 0.8 \\
\hline
\end{tabular}

Table 3. Formulation of fast dissolving tablets of Salbutamol Sulphate by Solid dispersion Technology

\begin{tabular}{|l|c|c|c|c|c|c|}
\hline Ingredients (mg) & C1 & C2 & C3 & C4 & C5 & C6 \\
\hline Salbutamol Sulphate & 4 & 4 & 4 & 4 & 4 & 4 \\
\hline PEG 4000 & 60 & 60 & 60 & 60 & 60 & 60 \\
\hline Sodium Starch Glycolate & 4 & 6 & & & & \\
\hline Crospovidone & & & 4 & 6 & & \\
\hline Ac-Di-Sol & & & & & 4 & 6 \\
\hline Avicel-PH 102 & 14 & 14 & 14 & 14 & 14 & 14 \\
\hline Mannitol & 16 & 14 & 16 & 14 & 16 & 14 \\
\hline Talc & 1 & 1 & 1 & 1 & 1 & 1 \\
\hline Magnesium Stereate & 0.2 & 0.2 & 0.2 & 0.2 & 0.2 & 0.2 \\
\hline Sodium Saccharine & 0.8 & 0.8 & 0.8 & 0.8 & 0.8 & 0.8 \\
\hline
\end{tabular}

\section{Evaluation of Blends}

Tablets were made from blends by direct compression method. There are many formulation and process variables involved in mixing step and all these can affect the characteristics of blends produced. The various characteristics of blends tested are as given below:

\subsection{Bulk and Tapped Density [11]}

The bulk density was determined by filling the processed base powders into a tared graduated cylinder to the $100 \mathrm{ml}$ mark. The graduated cylinder was weighed and the bulk density $\left(\mathrm{V}_{\mathrm{B}}\right)$ was calculated as the ratio of the sample weight to the sample volume. The graduated cylinders were then tapped from a height of above 2 inches till constant volume was obtained. The tap density $\left(\mathrm{V}_{\mathrm{T}}\right)$ was calculated as the ratio of the sample weight to the final sample volume. The trial was carried out on triplicate and the mean values were calculated.

\subsection{Haussner Ratio [11]}

Haussner factor (HF) was calculated from the following equation,

$$
\mathbf{H F}=\mathbf{V}_{\mathbf{T}} / \mathbf{V}_{\mathbf{B}}
$$

Where, $\mathrm{V}_{\mathrm{T}}$ and $\mathrm{V}_{\mathrm{B}}$ are tapped and bulk densities.

\subsection{Percent Compressibility [11]}

It is an important measure obtained from bulk density and is defined as,

$$
\mathbf{C}=\mathbf{V}_{\mathbf{B}}-\mathbf{V}_{\mathbf{T}} / \mathbf{V}_{\mathbf{B}} \mathbf{X 1 0 0} .
$$

If the bed of particles is more compressible will be less flowable and vice versa. Materials having " $C$ " values less than $20-21 \%$ is termed as free flowing materials.

\subsection{Angle of Repose [11]}

The frictional force in a loose powder can be measured by the angle of repose. It is defined as, the maximum angle possible between the surface of the pile of the powder and the horizontal plane. The angle of repose was determined by the funnel method suggested by Newman. Angle of repose is determined by the following formula 


$$
\operatorname{Tan} \theta=\mathbf{h} / \mathbf{r}
$$

Therefore

$$
\theta=\operatorname{Tan}^{-1} \mathbf{h} / \mathbf{r}
$$

Where $\theta=$ Angle of repose

$\mathrm{h}=$ height of the cone

$r=$ Radius of the cone base.

\section{Evaluation of Fast Dissolving Tablets [12]}

\subsection{Tablet Thickness}

Tablet thickness is an important characteristic in reproducing appearance and also in counting by using filling equipment. Ten tablets were taken and their thickness was recorded using micrometer.

\subsection{Uniformity of Weight}

I.P. procedure for uniformity of weight was followed, twenty tablets were taken and their weight was determined individually and collectively on a digital weighing balance. The average weight of one tablet was determined from the collective weight.

\subsection{Tablet Hardness}

Hardness of tablet is defined as the force applied across the diameter of the tablet in the order to break the tablet. The resistance of the tablet to chipping, abrasion or breakage under condition of storage transformation and handling before usage depends on its hardness. Hardness of the tablet of each formulation was determined using Monsanto Hardness tester.

\subsection{Friability}

It is measured of mechanical strength of tablets. Roche fribalator was used to determine the friability by following procedure. A preweighed tablet was placed in the fribalator. Fribalator consist of a plastic chamber that revolves at 25 rpm, dropping that tablet at a distance of 6 inches with each revolution. The tablets were rotated in the friabalator for at least 4 minutes. At the end of test tablets were dusted and reweighed, the loss in the weight of tablet is the measure of friability and is expressed in percentage as

\section{$\%$ Friability $=$ loss in weight $/$ Initial weight $\mathbf{X} 100$.}

\subsection{Disintegration Time}

The test was carried out on the 6 tablets. Artificial saliva at $37^{\circ} \mathrm{C} \pm 2{ }^{\circ} \mathrm{C}$ was used as a disintegration media and the time taken for complete disintegration of the tablet with no palpable mass remaining in the apparatus was measured in seconds.

\subsection{Wetting Time}

The method reported by yunixia et al., was followed to measure tablet wetting time. A piece of tissue paper $(12 \mathrm{~cm} \mathrm{X} 10.75 \mathrm{~cm})$ folded twice was placed in a small petridish $(\mathrm{ID}=6.5 \mathrm{~cm})$ containing $6 \mathrm{ml}$ artificial saliva. A tablet was put on the paper, and the time for complete wetting was measured. Three trials for each batch were performed and the standard deviation was also determined

\subsection{Drug Content}

Five tablets were powdered and the blend equivalent to $4 \mathrm{mg}$ of Salbutamol Sulphate was weight and dissolved in suitable quantity of buffer $\mathrm{pH}$ 6.8. Solution was filtered and diluted and drug content was analyzed spectrophotometrically at $276 \mathrm{~nm}$.

\subsection{In-vitro Dissolution Study}

The release of Salbutamol Sulphate from the tablet was accomplished in artificial saliva $(\mathrm{pH}$ 6.8) with a USP dissolution paddle assembly at $75 \mathrm{rpm}$ and a temperature of $37^{\circ} \mathrm{C} \pm 0.5^{\circ} \mathrm{C} .900 \mathrm{ml}$ was used as dissolution medium. Aliquot of dissolution medium $(5 \mathrm{ml})$ was withdrawn at specific time intervals (1 minute) and was filtered. The amount of drug release was determined spectrophotometrically at $276 \mathrm{~nm}$. An equal volume of fresh medium after each sampling to maintain the constant volume thought the test.

\subsection{Stability Studies}

Stability Studies of formulated tablets were carried out at $40 \mathrm{C}$ and $75 \% \mathrm{RH}$ using a stability chamber for one month. The effect of temperature and the time on the physical characteristics of tablets were evaluated for assessing the stability of prepared formulations. The different parameters tested were disintegration time, hardness, friability, drug content and dissolution rate.

\section{Results and Discussion}

\subsection{Characterization of Blend}

The characterization of mixed blend is shown in Table 4. The result shows that the Bulk density depends on the particle size, shape and tendency of particles to adhere together. It is also important in size hoppers and receivers for milling equipment and for size blending equipment. The results indicate good packaging capacity of tablets. The tapped density was found in the range of 0.365 to $0.525 \mathrm{gm} / \mathrm{cm}^{3}$. The powder blends of all the formulation had hausners ratio of 1.2 or less indicating the excellent flowability. The $\%$ compressibility index was found between $5.690 \%$ to $7.261 \%$. The $\%$ compressibility was below $16 \%$ showed excellent flow property of the powder was also evidenced by the angle of repose. The angle of repose was below then $30^{\circ}$ showed excellent flow properties of powder. Lower the friction occurring within the mass and better flow rate. This indicates the excellent flow property of the mixed blends.

\subsection{Characterization of Salbutamol Sulphate Fast Dissolving Tablets}

The prepared tablets were evaluated for diameter, Thickness, Hardness, weight variation, Friability, Disintegration time, 
wetting time. The results were tabulated in Table 5 . The average weight of the prepared tablet by direct compression, sublimation and solid dispersions was found 100.18 to $101.61 \mathrm{mg}, 100.09$ to $102.21 \mathrm{mg}$ and $100.05 \mathrm{mg}$ to $103.05 \mathrm{mg}$ respectively. The thickness of the tablet was found to be $2.5 \mathrm{~mm}$. The diameter of the tablets was found to be $7.1 \mathrm{~mm}$. The hardness of the prepared tablet varied from 3.08 to $4.71 \mathrm{~kg} / \mathrm{cm}^{2}$ which have satisfactory strength to withstand the mechanical shocks. The friability of all the formulation was found to be less than $0.5 \%$. The results shows resistance to loss of weight indicates the tablet's ability to withstand abrasion in handling, packaging and shipment. The disintegration time of the tablets was varied from 17 to 53 seconds. The wetting time of all the formulations were varied between 10 to 28 seconds.

Table 4. Characterization of blend

\begin{tabular}{|c|c|c|c|c|c|}
\hline Formulation & Bulk Density (mg/ml) & Tapped Density (mg/ml) & Hausner's Ratio & Compressibility Index (\%) & Angle of Repose $\mathbf{(}^{\mathbf{}}$ ) \\
\hline A1 & 0.346 & 0.365 & 1.075 & 7.210 & 26.54 \\
\hline A2 & 0.356 & 0.382 & 1.073 & 7.261 & 26.35 \\
\hline A3 & 0.363 & 0.389 & 1.071 & 7.210 & 25.36 \\
\hline A4 & 0.350 & 0.372 & 1.064 & 6.521 & 24.40 \\
\hline A5 & 0.358 & 0.381 & 1.064 & 6.346 & 23.61 \\
\hline A6 & 0.370 & 0.393 & 1.062 & 6.270 & 22.00 \\
\hline B1 & 0.464 & 0.492 & 1.060 & 6.130 & 21.71 \\
\hline B2 & 0.473 & 0.501 & 1.059 & 6.010 & 21.47 \\
\hline B3 & 0.481 & 0.509 & 1.058 & 5.914 & 21.10 \\
\hline B4 & 0.482 & 0.511 & 1.060 & 5.981 & 20.80 \\
\hline B5 & 0.484 & 0.513 & 1.059 & 5.883 & 20.50 \\
\hline B6 & 0.486 & 0.515 & 1.059 & 5.746 & 21.61 \\
\hline C1 & 0.487 & 0.516 & 1.060 & 5.934 & 20.74 \\
\hline C2 & 0.489 & 0.522 & 1.075 & 5.810 & 20.71 \\
\hline C3 & 0.492 & 0.524 & 1.077 & 5.710 & 20.60 \\
\hline C4 & 0.486 & 0.515 & 1.059 & 5.746 & 20.50 \\
\hline C5 & 0.487 & 0.517 & 1.060 & 5.834 & 20.10 \\
\hline C6 & 0.490 & 0.525 & 5.690 & \\
\hline
\end{tabular}

Table 5. Characterization of Salbutamol Sulphate fast dissolving tablets

\begin{tabular}{|l|c|c|c|c|c|c|c|}
\hline FC & Diameter (mm) & Thickness (mm) & Weight (mg) & Hardness (Kg/cm $)^{2}$ & Friability (\%) & $\begin{array}{c}\text { Disintegration } \\
\text { Time (Sec) }\end{array}$ & $\begin{array}{c}\text { Wetting Time } \\
\text { (Sec) }\end{array}$ \\
\hline A1 & 7.1 & 2.5 & $101.00 \pm 0.13$ & $4.29 \pm 0.4$ & $0.15 \pm 0.03$ & $53 \pm 1$ & $28 \pm 1$ \\
\hline A2 & 7.2 & 2.4 & $100.09 \pm 0.22$ & $3.88 \pm 0.2$ & $0.21 \pm 0.01$ & $51 \pm 1$ & $27 \pm 1$ \\
\hline A3 & 7.0 & 2.6 & $101.48 \pm 0.19$ & $4.33 \pm 0.1$ & $0.14 \pm 0.03$ & $34 \pm 1$ & $22 \pm 1$ \\
\hline A4 & 7.1 & 2.5 & $100.18 \pm 0.12$ & $4.09 \pm 0.3$ & $0.10 \pm 0.03$ & $30 \pm 2$ & $25 \pm 2$ \\
\hline A5 & 7.1 & 2.5 & $100.78 \pm 0.18$ & $3.08 \pm 0.2$ & $0.24 \pm 0.01$ & $37 \pm 1$ & $26 \pm 1$ \\
\hline A6 & 7.1 & 2.5 & $101.61 \pm .0 .39$ & $3.76 \pm 0.1$ & $0.17 \pm 0.02$ & $39 \pm 1$ & $24 \pm 1$ \\
\hline B1 & 7.1 & 2.5 & $100.89 \pm 0.41$ & $4.71 \pm 0.1$ & $0.13 \pm 0.03$ & $47 \pm 1$ & $27 \pm 2$ \\
\hline B2 & 7.1 & 2.5 & $100.09 \pm 0.21$ & $3.88 \pm 0.2$ & $0.23 \pm 0.01$ & $45 \pm 1$ & $23 \pm 1$ \\
\hline B3 & 7.1 & 2.5 & $100.11 \pm 0.22$ & $4.03 \pm 0.2$ & $0.16 \pm 0.01$ & $27 \pm 2$ & $16 \pm 2$ \\
\hline B4 & 7.1 & 2.5 & $100.89 \pm 0.57$ & $4.04 \pm 0.3$ & $0.13 \pm 0.02$ & $23 \pm 1$ & $14 \pm 1$ \\
\hline B5 & 7.1 & 2.5 & $101.87 \pm 0.27$ & $3.60 \pm .0 .2$ & $0.26 \pm 0.03$ & $34 \pm 1$ & $22 \pm 2$ \\
\hline B6 & 7.1 & 2.5 & $102.21 \pm 0.18$ & $3.92 \pm 0.3$ & $0.21 \pm 0.03$ & $33 \pm 1$ & $20 \pm 2$ \\
\hline C1 & 7.1 & 2.5 & $100.68 \pm 0.27$ & $3.45 \pm 0.2$ & $0.20 \pm 0.02$ & $35 \pm 1$ & $19 \pm 1$ \\
\hline C2 & 7.1 & 2.5 & $100.21 \pm 0.18$ & $3.32 \pm 0.3$ & $0.39 \pm 0.02$ & $34 \pm 1$ & $18 \pm 2$ \\
\hline C3 & 7.1 & 2.5 & $103.05 \pm 0.58$ & $3.45 \pm 0.3$ & $0.24 \pm 0.01$ & $18 \pm 1$ & $11 \pm 2$ \\
\hline C4 & 7.1 & 2.5 & $100.75 \pm 0.64$ & $3.65 \pm 0.2$ & $0.21 \pm 0.02$ & $17 \pm 1$ & $10 \pm 1$ \\
\hline C5 & 7.1 & 2.5 & $100.05 \pm 0.58$ & $3.76 \pm 0.1$ & $0.24 \pm 0.01$ & $25 \pm 1$ & $17 \pm 2$ \\
\hline C6 & 7.1 & 2.5 & $101.75 \pm 0.64$ & $3.09 \pm 0.2$ & $0.21 \pm 0.02$ & $24 \pm 1$ & $15 \pm 1$ \\
\hline
\end{tabular}




\subsection{In Vitro Drug Release Profile}

In vitro drug release experiments were performed at $37 \pm 1{ }^{\circ} \mathrm{C}$ in six basket dissolution rate apparatus. The data obtained in vitro drug release study are tabulated. The result showed that all the formulation releases the drug in 5 to 6 minutes. The maximum drug release was found in formulation $\mathrm{C} 4$. The data from $\mathrm{C} 1$ to $\mathrm{C} 6$ formulations are represented graphically showing $\mathrm{C} 4$ as the best formulation.

Table 6. In vitro release data of Salbutamol Sulphate from A1 to A6

\begin{tabular}{|c|c|c|c|c|c|c|}
\hline Time (min.) & $\mathbf{A 1}$ & $\mathbf{A 2}$ & $\mathbf{A 3}$ & $\mathbf{A 4}$ & $\mathbf{A 5}$ & $\mathbf{A 6}$ \\
\hline 0.000 & 0 & 0 & 0 & 0 & 0 & 0 \\
\hline 0.500 & 30.70 & 32.62 & 44.78 & 46.91 & 41.61 & 42.16 \\
\hline 1.000 & 58.28 & 66.67 & 79.78 & 81.90 & 76.10 & 78.46 \\
\hline 2.000 & 65.07 & 78.82 & 86.80 & 87.01 & 82.79 & 84.28 \\
\hline 3.000 & 79.61 & 80.49 & 91.37 & 90.93 & 87.96 & 89.20 \\
\hline 4.000 & 80.69 & 85.40 & 94.07 & 93.10 & 89.81 & 90.41 \\
\hline 5.000 & 82.90 & 88.90 & 95.86 & 96.79 & 91.21 & 93.12 \\
\hline
\end{tabular}

Table 7. In vitro release data of Salbutamol Sulphate tablet of B1 to B6

\begin{tabular}{|c|c|c|c|c|c|c|}
\hline Time (min.) & B1 & B2 & B3 & B4 & B5 & B6 \\
\hline 0.000 & 0 & 0 & 0 & 0 & 0 & 0 \\
\hline 0.500 & 33.757 & 35.669 & 46.123 & 48.081 & 43.906 & 44.043 \\
\hline 1.000 & 71.134 & 70.418 & 76.807 & 75.966 & 72.607 & 73.256 \\
\hline 2.000 & 75.140 & 78.913 & 81.377 & 88.251 & 79.913 & 81.214 \\
\hline 3.000 & 80.238 & 81.486 & 88.238 & 90.190 & 83.646 & 89.283 \\
\hline 4.000 & 81.487 & 83.789 & 93.073 & 96.637 & 89.256 & 90.209 \\
\hline 5.000 & 82.530 & 84.665 & 96.948 & 97.612 & 94.926 & 96.191 \\
\hline
\end{tabular}

Table 8. In vitro release data of Salbutamol Sulphate tablet of $\mathrm{C1}$ to $\mathbf{C 6}$

\begin{tabular}{|c|c|c|c|c|c|c|}
\hline Time (min.) & C1 & $\mathbf{C 2}$ & $\mathbf{C 3}$ & $\mathbf{C 4}$ & $\mathbf{C 5}$ & $\mathbf{C 6}$ \\
\hline 0.000 & 0 & 0 & 0 & 0 & 0 & 0 \\
\hline 0.500 & 38.730 & 38.557 & 45.227 & 46.789 & 43.351 & 43.656 \\
\hline 1.000 & 70.2 & 73.651 & 75.154 & 78.256 & 74.212 & 73.283 \\
\hline 2.000 & 79.637 & 77.814 & 86.190 & 89.214 & 87.647 & 85.814 \\
\hline 3.000 & 80.154 & 83.215 & 90.387 & 91.522 & 90.003 & 94.211 \\
\hline 4.000 & 81.251 & 85.257 & 98.966 & 97.657 & 94.651 & 97.547 \\
\hline 5.000 & 82.142 & 88.633 & 99.021 & 99.918 & 96.990 & 98.063 \\
\hline
\end{tabular}

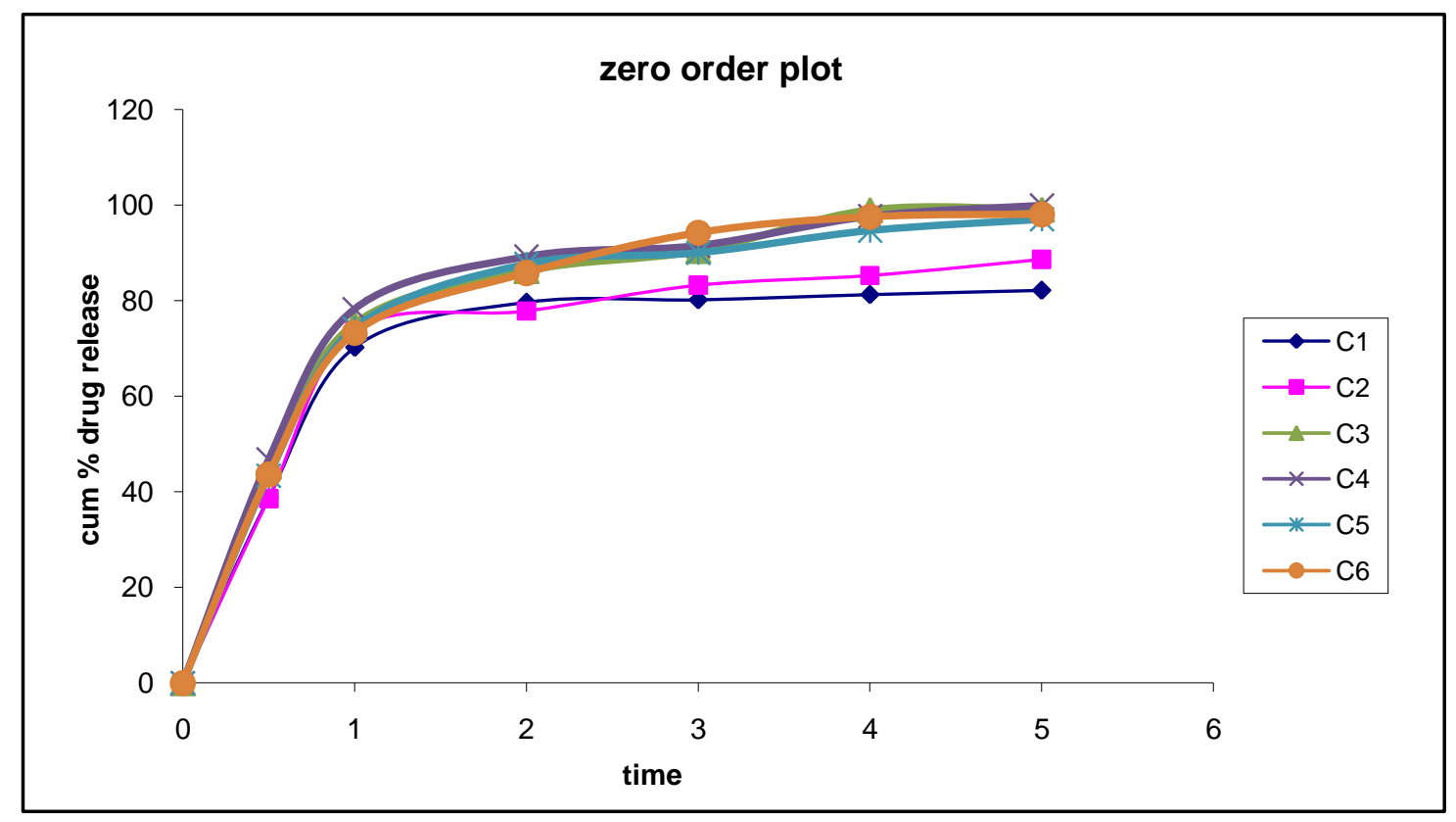

Figure 1. Zero order plot for different formulations $\left(\mathrm{C}_{1}-\mathrm{C}_{6}\right)$

Table 9. Stability study data of the tablet formulations

\begin{tabular}{|c|c|c|c|c|c|c|}
\hline Formulation & Thickness $(\mathbf{m m})$ & Weight $\mathbf{( m g})$ & Hardness $\left.\mathbf{( K g} / \mathbf{c m}^{2}\right)$ & Friability $\mathbf{( \% )}$ & Disintegration Time(Sec) & Wetting Time (Sec) \\
\hline A4 & 2.5 & $101.18 \pm 0.12$ & $3.66 \pm 0.3$ & $0.15 \pm 0.03$ & $28 \pm 2$ & $23 \pm 2$ \\
\hline B4 & 2.5 & $100.89 \pm 0.77$ & $3.97 \pm 0.1$ & $0.19 \pm 0.02$ & $22 \pm 1$ & $11 \pm 1$ \\
\hline C3 & 2.5 & $101.05 \pm 0.88$ & $3.19 \pm 0.4$ & $0.25 \pm 0.01$ & $16 \pm 1$ & $10 \pm 2$ \\
\hline C4 & 2.5 & $101.75 \pm 0.64$ & $3.65 \pm 0.1$ & $0.23 \pm 0.02$ & $15 \pm 1$ & $10 \pm 1$ \\
\hline
\end{tabular}

\subsection{Stability Studies}

Stability studies were conducted of the selected formulation (A4, B4, C3, C4). The formulation were stored at accelerated $(40 \pm 20 / 75 \pm 5 \% \mathrm{RH})$ conditions in stability chamber for 1 month. After the stability period tablets were tested for thickness, weight, hardness, friability, disintegration time and wetting time.

The results show that both disintegration and hardness values decreased significantly indicating that tablets have lost the mechanical integrity leading to more friability loss. At higher relative humidity, tablet containing high concentration of super disintegrants gets softened and hence, must be protected from atmospheric moisture.

\section{Conclusion}

The objective of the present investigation was to formulate and evaluate fast dissolving tablet of Salbutamol Sulphate. The water soluble drug would be readily available in a dissolved form for rapid oral uptake. 
The rapid dissolving concept in case of Salbutamol Sulphate could be of a great importance in reliving acute asthmatic shocks. From the above experimental findings it can be concluded that Fast dissolving tablets prepared by solid dispersion technique using Crospovidone as a superdisintegrant shows less disintegration time compared with others.

\section{References}

[1] Bradoo R, Shahani S, Poojary S, Deewan B, Sudarshan S. Fast Dissolving Drug Delivery Systems. JAMA 2001; 4: 27-31.

[2] Dobetti L. Fast-Melting Tablets: Development and Technologies. Pharm Tech 2001; 37: 44-50.

[3] Lorenzp Lamosa ML, Cuna M, Vila-Jato JL, Torres D. Fast Dissolving Drug Delivery Systems: An Update. J Microencapsul 1997; 14: 607.

[4] Chang RK, Guo X, Burnside BA, Couch RA. Fast-dissolving Tablets. Pharm Tech 2000; 24: 52-58.
[5] Caraballo I, Fernandez-Arevalo M, Millan M. Superdisintegrants in Tablet Formulations. Drug Dev Ind Pharm 1997; 23: 665-669.

[6] Nayak AK, Manna K. Current developments in orally disintegrating tablet technology. Journal of Pharmaceutical Education and Research 2011; 2(1): 21-34.

[7] Sreenivas SA, Dandagi PM, Gadad AP, Orodispersible tablet: new drug delivery system - a review. Indian Journal of Pharmaceutical Education and Research 2005; 39(4): 177-181.

[8] Bhowmik D, Chiranjib B, Pankaj K, Chandira MR, Fast dissolving tablet: an overview. Journal of Chemical and Pharmaceutical Research 2009; 1(1): 163-177.

[9] Prajapati BG, Ratnakar N. A review on recent patents on fast dissolving drug delivery system. International Journal of PharmTech Research 2009; 1(3): 790-798.

[10] Chandira MR, Bhowmik DC, Gosh NS, Sahu SR. Studies on resent aspect of mouth dissolving tablet- an overview. Life science 2009; 1:1-19.

[11] Liberman H.A, Lachman L. In Pharmaceutical Dosage Form: Tablets, 2, Marcell Dekker, Inc, New York.1991; 123: 209-215.

[12] Sunada H, Yonezawa Y, Danjo K. Studies on evaluation of rapidly disintegrating tablets prepared by direct compression method. Drug Dev Ind Pharm 1999; 25: 571-581. 